\title{
Intoxicação experimental por Froelichia humboldtiana em equinos
}

\author{
Experimental poisoning by Froelichia humboldtiana in horses
}

Rosane Maria Trindade Medeiros ${ }^{\mathrm{I}^{*}}$ Von Klein Dantas Bezerra ${ }^{\mathrm{I}}$ Franklin Riet-Correa $^{\mathrm{I}}$

\section{- NOTA -}

\section{RESUMO}

Surtos de fotossensibilização primária em equídeos associados à ingestão de Froelichia humboldtiana, são frequentes na região semiárida do Nordeste. A reprodução experimental da doença foi realizada em uma fazenda do município de Parelhas, Rio Grande do Norte, utilizando três equinos, dois experimentais e um controle. Os equinos experimentais permaneceram por 16 dias presos a cordas de 10 metros cada uma, em área invadida pela $\boldsymbol{F}$. humboldtiana. A corda era fixada a cada dia em local diferente $e$ outras plantas da área de pastejo que não $\boldsymbol{F}$. humboldtiana eram arrancadas. $O$ equino controle permaneceu em área isenta da $\boldsymbol{F}$. humboldtiana. A partir do $4^{o}$ dia de pastejo, os equinos experimentais começaram a apresentar prurido e queda de pelo nas áreas despigmentadas do chanfro, focinho, boleto e quartela, progredindo para vermelhidão, exsudato e formação de crostas, nos dias subsequentes. Não foram observadas alterações nas atividades séricas de aspartato aminotransferase, gama-glutamil transferase, lactato desidrogenase e fosfatase alcalina. A planta mostrou-se altamente palatável para os equinos. Não foi observada nenhuma alteração no equino controle. Os resultados comprovam que $\boldsymbol{F}$. humboldtiana causa fotossensibilização primária em equinos após a ingestão de grandes quantidades de planta.

Palavras-chave: dermatite, equídeos, fotossensibilização primária, plantas tóxicas.

\section{ABSTRACT}

Outbreaks of primary photosensitization associated with the ingestion of Froelichia humboldtiana are frequent in equidae in the Brazilian semiarid region. To reproduce experimentally the poisoning, two experimental horses were tied by a rope, in different places in a pasture of exclusively $\boldsymbol{F}$. humboldtiana for a 16 days period. A control horse grazed in another area without $\boldsymbol{F}$. humboldtiana. After four days both horses in the paddock with $\boldsymbol{F}$. humboldtiana showed reddening and alopecia of the white regions of the body. After 16 days lesions were more severe with exudates and crusts. No lesions were observed in the control horse. Serum activities of $\gamma$-glutamyltransferase, aspartate aminotransferase, alkaline phosphatase, and lactate dehydrogenase were within normal values. F. humboldtiana was very palatable for the horses. These results demonstrate that $\boldsymbol{F}$. humboldtiana causes primary photosensitization in horses after the ingestion of large amounts of plant.

Key words: dermatitis, equidae, primary photosensitization, toxic plants.

Froelichia humboldtiana Roem. \& Schult., da família Amaranthaceae (Figura 1A), conhecida popularmente como ervanço, foi descrita como causa de fotossensibilização primária em equídeos, ovinos e bovinos (MACEDO et al., 2006; RIET-CORREA et al., 2006; PIMENTEL et al., 2007; SOUZA et al., 2012) na região semiárida do Nordeste do Brasil. A doença ocorre tanto no Agreste quanto no Carirí e no Sertão, afetando preferencialmente equídeos, no período de chuvas, principalmente no final deste, de março a maio, em pastagens invadidas por $\boldsymbol{F}$. humboldtiana. A intoxicação foi reproduzida experimentalmente em ovinos (PIMENTEL et al., 2007) e bovinos (SOUZA et al., 2012). Em equinos e asininos, tentativas de reprodução experimental da intoxicação, administrando $\boldsymbol{F}$. humboldtiana imediatamente após a coleta ou após ela ter sido conservada em geladeira, tiveram resultados negativos (PIMENTEL et al., 2007). O objetivo deste trabalho foi reproduzir experimentalmente a enfermidade em equinos e determinar aspectos epidemiológicos da doença nesta espécie.

'Hospital Veterinário, Universidade Federal de Campina Grande (UFCG), 58700-000, Patos, PB, Brasil. E-mail: rmtmed@uol.com.br. *Autor para correspondência. 


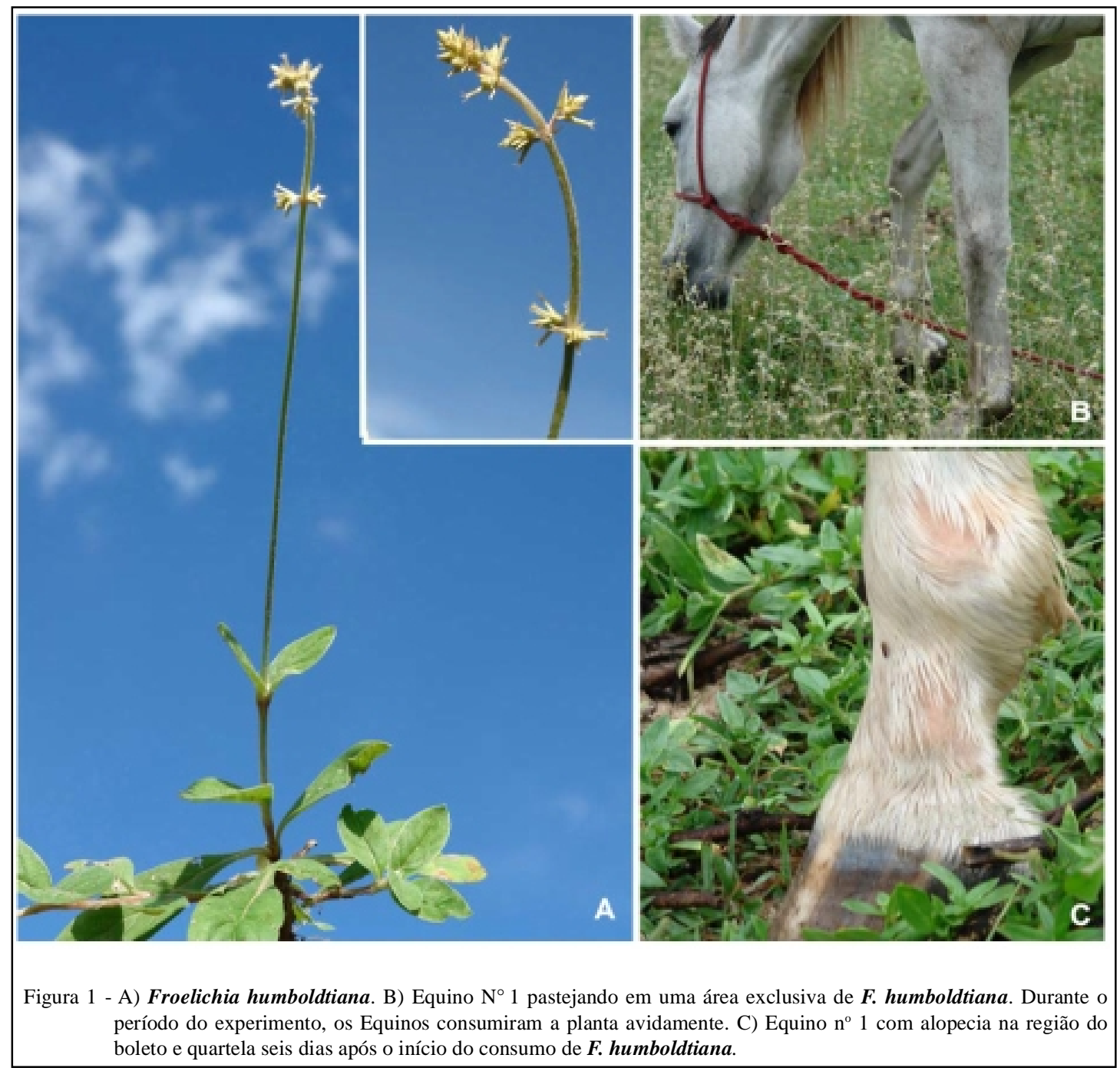

$\mathrm{O}$ experimento foi realizado na região do Séridó, no município de Parelhas, na fazenda São Sebastião. No experimento, foram utilizados três equinos adultos, fêmeas, mestiças da raça quarto de milha. Foram utilizados dois equinos experimentais, um de pelagem tordilha $\left(\mathrm{n}^{0} 1\right)$, com uma área do chanfro e os jarretes despigmentados, com três anos de idade e outro de pelagem alazã $\left(n^{\circ} 2\right)$, com chanfro branco e com as quatro patas brancas, com dois anos e oito meses de idade. $\mathrm{O}$ terceiro equino $\left(\mathrm{n}^{\circ} 3\right)$, controle, era também alazã, com o chanfro branco, com cinco anos de idade.

O experimento começou um mês após o início das chuvas, quando $\boldsymbol{F}$. humboldtiana já estava com $30 \mathrm{~cm}$ de altura e predominava na área, com intensa floração e desenvolvimento de pendão. No dia 21/03/2009, os equinos experimentais foram colocados em um cercado com aproximadamente 5 hectares, com pastagem quase que exclusiva de $\boldsymbol{F}$. humboldtiana. Cada um dos equinos experimentais era preso a cordas de 10 metros, fixadas ao solo por meio de estacas (Figura 1B). A corda era fixada a cada dia em local diferente. Os equinos eram observados três vezes ao dia: pela manhã; ao meio dia, quando se fornecia água; e ao fim da tarde, para observar se os equinos continuavam presos à corda. Em nenhum momento, os equinos experimentais saíram da área de pastoreio. $\mathrm{O}$ fornecimento de água foi por meio de cochos fixados em locais que cada animal pudesse beber a vontade em seu respectivo cocho. Em dias alternados, era fornecida uma mistura de concentrado ( $1,5 \mathrm{~kg}$ de farelo milho e $1 \mathrm{~kg}$ de farelo de trigo) para cada animal. Diariamente, eram retiradas das áreas a serem pastejadas pelos animais outras plantas que não fossem $\boldsymbol{F}$. humboldtiana. O equino controle foi colocado solto em uma área de aproximadamente 4 
hectares que não havia $\boldsymbol{F}$. humboldtiana e recebia a mesma suplementação que os equinos experimentais. No início do experimento, todos os equinos foram vermifugados e realizado exame clínico.

Foram coletadas amostras de sangue dos equinos em três períodos distintos: imediatamente antes do início do experimento (20/03/09); com oito dias de pastoreio, quando nos animais experimentais já evidenciavam lesões nas áreas despigmentadas; e com 16 dias de pastoreio. Em cada coleta, foram analisados os níveis séricos de aspartato aminotransferase (AST), gama glutamil transferase (GGT), fosfatase alcalina (FA) e lactato desidrogenase (LDH), utilizando o método cinético com kits comerciais da Bioclin ${ }^{\circledR}$.

Os equinos experimentais apresentaram prurido e queda de pelo, mais acentuados nas áreas despigmentadas, a partir do $4^{\circ}$ dia de experimento. Nesse dia, observou-se que o chanfro do Equino 1, e o focinho do Equino 2 estavam mais rosados. No sexto dia, observou-se queda de pelo da região do boleto e quartela esquerdos do Equino 1 (Figura 1C) e no focinho dos dois equinos, sendo mais acentuada no Equino 2. No sétimo dia, nos dois equinos, as lesões na área do focinho eram mais marcadas, havia aumento de queda de pelo das áreas despigmentadas e avermelhamento e alopecia na região do chanfro e do boleto e quartela esquerdos. Essas lesões foram aumentando e, na última observação, realizada dia 12 de abril de 2009, os equinos apresentavam exsudato e formação de crostas, nas três áreas citadas. No $16^{\circ}$ dia, os equinos foram retirados da área e colocados na sombra, observando-se recuperação total das lesões após 7 a 14 dias. Não foram observadas alterações clínicas no Equino 3 (controle). As atividades séricas de AST, GGT, FA e LDH de todos os animais estavam dentro dos valores normais, tanto antes do experimento quanto no final dele, com 16 dias de ingestão da planta (Tabela 1).

A presença de lesões nas áreas despigmentadas, nos equinos que pastejavam em área invadida por $\boldsymbol{F}$. humboldtiana, e a ausência destas no equino controle, que pastejou por período integral em área sem a planta, comprovam que a doença é causada por $\boldsymbol{F}$. humboldtiana. Similares resultados foram obtidos por PIMENTEL et al. (2007) em ovinos e por SOUZA et al. (2012) em bovinos. Experimentos com a planta arrancada, conservada em geladeira e posteriormente administrada à vontade a asininos, equinos e ovinos, por 30 dias, não reproduziram lesões de fotossensibilização (PIMENTEL et al., 2007). É possível que a planta perca a toxicidade após ser coletada e armazenada, semelhante ao que ocorre com Hipericum perforatum, cujo princípio ativo (hipericina) é uma substância derivada da naftodiantrona, a qual, após a fenação, perde $80 \%$ da toxicidade (MUNRO, 2006).

Os valores séricos de AST, FA, GGT e LDH, dentro da normalidade, nos equinos que pastaram durante 16 dias em área invadida por $\boldsymbol{F}$. humboldtiana e apresentaram sinais de fotossensibilização, comprovam que a planta causa fotossensibilização primária, sem comprometimento hepático.

Foi evidenciado neste experimento que $\boldsymbol{F}$. humboldtiana é altamente palatável para equinos, o que faz com que estes animais a ingiram avidamente. Este fato e a ocorrência de áreas onde a planta é a espécie dominante são fatores aparentemente determinantes para a ocorrência da intoxicação. Neste experimento, a ingestão de $\boldsymbol{F}$. humboldtiana como único alimento volumoso causou fotossensibilização, quatro dias após o início do consumo, enquanto que, em ovinos em condições semelhantes às primeiras lesões, foram observadas 4-11 dias após o início da ingestão e, em bovinos, após 3 dias de consumo, o que evidencia susceptibilidade semelhante entre as 3 espécies. No entanto, a doença é bem mais frequente em equinos do que em ovinos ou bovinos (MACEDO et al., 2006; RIET-CORREA et al., 2006), o que poderia ser devido à grande palatabilidade da planta para os equinos, que a ingerem com avidez.

A localização das lesões no chanfro e parte distal dos membros sugere a possibilidade de que $\boldsymbol{F}$. humboldtiana cause fotossensibilização também em consequência do contato com a pele. Porém o fato de

Tabela 1 - Valores (U/L) de aspartato aminotransferase (AST), gama glutamil transferase (GGT), fosfatase alcalina (FA) e lactato desidrogenase (LDH) em dois equinos pastando em área invadida por Froelichia humboldtiana e em um equino controle que pastoreava em área onde não havia essa planta.

\begin{tabular}{|c|c|c|c|c|c|c|c|c|c|c|c|c|}
\hline \multirow[t]{2}{*}{ Equino $\left(\mathrm{N}^{\circ}\right)$} & \multicolumn{4}{|c|}{--------------------Dia 0------------------- } & \multicolumn{4}{|c|}{ 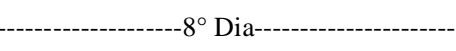 } & \multicolumn{4}{|c|}{ 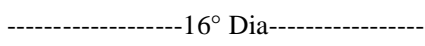 } \\
\hline & GGT & AST & FA & $\mathrm{LDH}$ & GGT & AST & FA & $\mathrm{LDH}$ & GGT & AST & FA & $\mathrm{LDH}$ \\
\hline 1 Tratado & 14 & 256 & 543 & 192 & 14 & 312 & 361 & 148 & 16 & 289 & 328 & 104 \\
\hline 2 Tratado & 14 & 274 & 286 & 128 & 19 & 359 & 314 & 196 & 10 & 328 & 237 & 184 \\
\hline 3 Controle & 8 & 254 & 245 & 176 & 8 & 256 & 245 & 176 & 10 & 242 & 259 & 136 \\
\hline
\end{tabular}


que animais afetados espontaneamente apresentam lesões no dorso, área de difícil possibilidade de contato com a planta, e as grandes quantidades de planta ingerida evidenciam que a via oral é a mais importante para a ocorrência da doença.

\section{COMITÊ DE ÉTICA E BIOSSEGURANÇA}

Declaração dos autores:

Nós, autores do artigo intitulado "Intoxicação experimental por Froelichia humboldtiana em equinos", declaramos, para os devidos fins, que o projeto que deu origem aos dados deste trabalho não foi submetido para avaliação ao Comitê de Ética da Universidade Federal de Campina Grande, mas estamos cientes do conteúdo das resoluções do Conselho Nacional de Controle de Experimentação Animal - CONCEA <http://www. mct.gov.br/index.php/content/view/310553.html> caso envolva animais. Dessa forma, os autores assumem total responsabilidade pelos dados apresentados e estão disponíveis para possíveis questionamentos, caso venham a ser requeridos pelos órgãos competentes.

\section{AGRADECIMENTOS}

Este trabalho foi financiado pelo Instituto Nacional de Ciência e Tecnologia (INCT) Para o estudo do Controle das Intoxicações por Plantas.

\section{REFERENCIAS}

MACEDO, M.C. et al. Fotossensibilização em animais de produção na região semiárida do Rio Grande do Norte. Arquivos do Instituto Biológico, São Paulo, v.73, n.2 p.251-254, 2006. Disponível em: <http://www.biologico.sp.gov.br/docs/arq/V73_2/ macedo.PDF>. Acesso em: 27 fev. 2012.

MUNRO, D.B. Canadian poisonous plants information system. Notes on poisoning: Hypericum perforatum. 2006. Disponível em: 〈http://sis.agr.gc.ca/pls/pp/poison?p_x=px>. Acesso em: 12 ago. 2006.

PIMENTEL, L.A. et al. Fotossensibilização primária em equídeos e ruminantes no semiárido causada por Froelichia humboldtiana (Amaranthaceae). Pesquisa Veterinária Brasileira, v.27, p.19-24, 2007. Disponível em: <http://www.scielo.br/scielo. php?script=sci_pdf\&pid=S0100-736X2007000100005\&lng=pt\& nrm=iso\&tlng=pt>. Acesso em: 10 jul. 2012. doi: 10.1590/S0100736X2007000100005

RIET-CORREA, F. et al. Plantas tóxicas da Paraíba. Patos: CSTR/UFCG, SEBRAE/PB, 2006. 58p.

SOUZA, P.E.C. et al. Primary photosensitization in cattle caused by Froelichia humboldtiana. Research in Veterinary Science, v.88, p.1337-1340, 2012. Disponível em: <http://www.sciencedirect. com/science/article/pii/S0034528812001233>. Acesso em: $10 \mathrm{jul}$. 2013. doi: $10.1016 /$ j.rvsc.2012.04.005. 